\title{
DETERMINAÇÃO DA ATIVIDADE DE SEQUESTRO DE RADICAL LIVRE DPPH• DE EXTRATO E FRAÇÕES DA ESPÉCIE Calophyllum brasiliense (JACAREÚBA)
}

\author{
F. M. S. $\operatorname{COSTA}^{1}$, A. R. NUNES ${ }^{1}$, G. A. $\operatorname{SILVA}^{1}$, F. T. SOBRAL ${ }^{2}$ e D. C. SANTOS ${ }^{1}$ \\ ${ }^{1}$ Universidade do Estado do Amapá \\ ${ }^{2}$ Faculdade Estácio do Amapá \\ E-mail para contato: fmanuelascosta@gmail.com
}

\begin{abstract}
RESUMO - Os compostos antioxidantes são responsáveis pela inibição de radicais livres, estes são produzidos naturalmente pelo organismo e causam efeitos danosos aos sistemas como o estresse oxidativo que tem relação com disfunções celulares como o câncer e doenças degenerativas. A ação de antioxidantes naturais tem ganhado destaque, com ênfase aos compostos relacionados a plantas. Com o objetivo de caracterizar a atividade de sequestro de radical livre da espécie Calophyllum brasiliense, coletada no estado do Amapá, realizou-se o preparo dos extratos através das cascas da planta e também a preparação do extrato bruto, frações clorofórmio, acetato de etila e fração residual para análise da atividade sequestradora do radical livre $\mathrm{DPPH} \bullet$, com leitura a

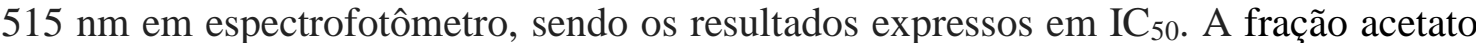
de etila obteve melhor resultado, apresentando sequestro de radical livre (SRL) igual a $2,93 \pm 0,08 \mu \mathrm{g} / \mathrm{mL}$, seguido da fração residual que apresentou $4,01 \pm 0,20 \mu \mathrm{g} / \mathrm{mL}$ e extrato bruto com $6,91 \pm 0,22 \mu \mathrm{g} / \mathrm{mL}$, entretanto a fração clorofórmio obteve resultado insatisfatório comparado aos demais, com seu SRL respectivamente igual a 26 $\pm 1,39$ $\mu \mathrm{g} / \mathrm{mL}$, tal resultado pode ser relacionado ao alto teor de polifenóis.
\end{abstract}

\section{INTRODUÇÃO}

Os radicais livres são moléculas orgânicas quimicamente instáveis e reativas, devido apresentarem um ou mais elétrons não pareados, sua formação em organismos vivos decorre via ação catalítica enzimática e exposição a fatores exógenos, suas atuações são as mais diversas, tais como na produção de energia, regulação do desenvolvimento celular, fagocitose e outros (ALVES et al. 2010). Contudo sua presença em excesso pode ocasionar efeitos danosos aos sistemas sendo prejudicial para a manutenção de várias funções fisiológicas tida como normais exemplos comuns são os danos ao DNA, proteínas, organelas celulares e outros (HAIDA et al. 2014; SOUSA et al. 2007), esta ação também é conhecida como estresse oxidativo por haver uma desproporcionalidade entre as moléculas oxidantes e antioxidantes (BIANCHI e ANTUNES. 1999), por isso a sua relação com disfunções celulares, sendo assim as mais conhecidas: o câncer, envelhecimento precoce e doenças degenerativas (FANHAN \& FERREIRA. 2006).

Nesse contexto, o emprego de compostos antioxidantes, que podem ser obtidos através de dietas ou em forma sintética e disponível por meio das indústrias de bebidas, cosméticos, alimentos e outros, é um dos artifícios usados contra a ação dos radicais livres (BIANCHI e ANTUNES. 1999). Estes compostos possuem a característica de que quando presentes em 
concentrações baixas em relação ao substrato oxidável são capazes de realizar a inibição da oxidação de tal substrato, desta forma como resultado tem-se radicais não reativos para a capacidade de propagação em cadeia e sua neutralização se dá por meio de reações com outros radicais (SOUSA et al. 2007). Os estudos envolvendo antioxidantes naturais, especificamente relacionados a plantas, tem cada vez mais ganhado destaque perante a comunidade científica (HAIDA et al. 2013), em virtude dos mesmos apresentarem semelhança ou superioridade aos antioxidantes sintéticos quanto ao bloqueio da oxidação, maior confiabilidade, potencial nutricional e efeitos terapêuticos (MILITÃO e FURLAN. 2014)

O Estado do Amapá possui um litoral estuarino com vegetações inigualáveis, devido a performance do rio Amazonas. A espécie Calophyllum brasiliense, também conhecida popularmente como guanandi, guarandi, jacareúba e outros, ocorre em vegetações de várzeas e igapós (SOUSA et al. 2007), caracteriza-se por ser uma espécie heliófita ou de luz difusa. Sua empregabilidade esta associada à apicultura e como forrageira, de sua casca é extraído o bálsamo de jacareúba para o uso em tratamento de úlceras e tumores, o óleo oriundo da semente tem aplicabilidade indústria (BOTREL et al. 2006). Segundo Navarro (2007) a madeira da espécie tem aplicação que passa pela construção civil, fluvial, marcenaria, compensados, papel e barris para vinho.

Mesmo com várias aplicabilidades esta espécie não apresenta muitos estudos quanto a sua atividade antioxidante e a partir do exposto o presente trabalho visa como objetivo realizar a caracterização da atividade de sequestro de radical livre $\mathrm{DPPH} \bullet$ de extrato e frações da espécie Calophyllum brasiliense (jacareúba) coletada no Estado do Amapá no mês de agosto de 2016.

\section{MATERIAL E MÉTODOS}

\subsection{Obtenção e preparo dos extratos}

A obtenção das amostras da espécie Calophyllum brasiliense no mês de agosto de 2016 no município de Magazão-Ap se deu através da parceria com o Instituto de Pesquisas Cientificas e Tecnológicas do Estado do Amapá (IEPA). No Laboratório de Química Orgânica e Bioquímica da Universidade do Estado do Amapá (UEAP) as cascas das amostras foram reduzidas e maceradas em etanol:água (70:30 p/p) por 4 dias/temperatura ambiente/agitações periódicas e banho ultrassom por 15 minutos/dia. Após filtrações a vácuo o volume dos filtrados foi mensurado e concentrado em rotaevaporador $\left(40^{\circ} \mathrm{C} /\right.$ pressão negativa), resultando em extrato bruto, este também subsidiou o preparo da fração clorofórmio no qual foram usados $250 \mathrm{ml}$ de extato bruto para $400 \mathrm{ml}$ de clorofórmio, após $48 \mathrm{~h}$ a fase orgânica foi retirada e adicionado $400 \mathrm{ml}$ do reagente acetato de etila, em ambos os casos o processo foi realizado por partição líquido-líquido, após $48 \mathrm{~h}$ a fase orgânica foi recolhida dando origem as fração acetato de etila e a fração de extrato bruto contida no funil foi denomida de fração residual, todas as frações auxiliaram a caracterização da atividade de sequestro de radical livre DPPH da espécie Calophyllum brasiliense (jacareúba). 


\subsection{Determinação da atividade de sequestro do radical livre}

Um dos métodos mais utilizados para a determinação da atividade do sequestro do radical livre baseia-se em analisar a atividade seqüestradora do radical livre 2,2-difenil-1-picrilhidrazila - DPPH•, que apresenta coloração púrpura. Isto ocorre devido à presença de um antioxidante ou uma espécie radicular, assim o DPPH• é reduzido dando origem ao difenilpicril-hidrazina, que manifesta coloração amarelada. Após a leitura dos resultados em espectofotômetro a $515 \mathrm{~nm}$ é possível estipular a porcentagem de atividade antioxidante (AA\%), que condiz com a quantidade de DPPH consumida pelo antioxidante, desta forma a quantidade de antioxidante essencial para fazer com que a concentração inicial de DPPH diminua em $50 \%$ é chamada de concentração inibitória $\left(\mathrm{IC}_{50}\right)$. Como conclusão, tem-se que quando o consumo de DPPH for mais expressivo por uma determinada amostra, o resultado será um IC 50 de baixa intensidade e em contra partida sua atividade antioxidante será maior. (SOUSA et al. 2007)

\section{RESULTADOS E DISCUSSÃO}

A realização da avaliação quantitativa da atividade antioxidante foi realizada segundo a metodologia usada por Brand-Williams et al. (1995), assim o acompanhamento referente a taxa do consumo do radical livre DPPH pelas amostras deu-se por meio da diminuição da absorbância das soluções de diferentes concentrações. Neste caso, as analises ocorreram em espectrofotômetro (biospectro sp-22) no comprimento de onda $515 \mathrm{~nm}$, tendo como controle positivo metanol.

As medidas de absorbância foram efetuadas em duplicata. Para a equação da curva de calibração do DPPH foram adotadas seis concentrações distintas da solução padrão, a partir dos valores obtidos em absorbância, um gráfico de dispersão foi plotado para a observação da curva de calibração e de maneira estatista os coeficientes de correlação $\left(R^{2}=0,9985\right)$, coeficiente angular $(a=0,0068)$ e intersecção no eixo y $(b=0,0138)$.

Os resultados do sequestro do radical livre DPPH. pelos compostos químicos dos extratos hidroalcoólicos das cascas de Calophyllum brasilienses foram expressos em $\mathrm{IC}_{50}$ $(\mu \mathrm{g} / \mathrm{mL})$, como apresentados na Figura 1.

Figura 1: Atividade de sequestro do radical livre DPPH da amostra da espécie Calophyllum brasiliense no mês de agosto de 2016. 


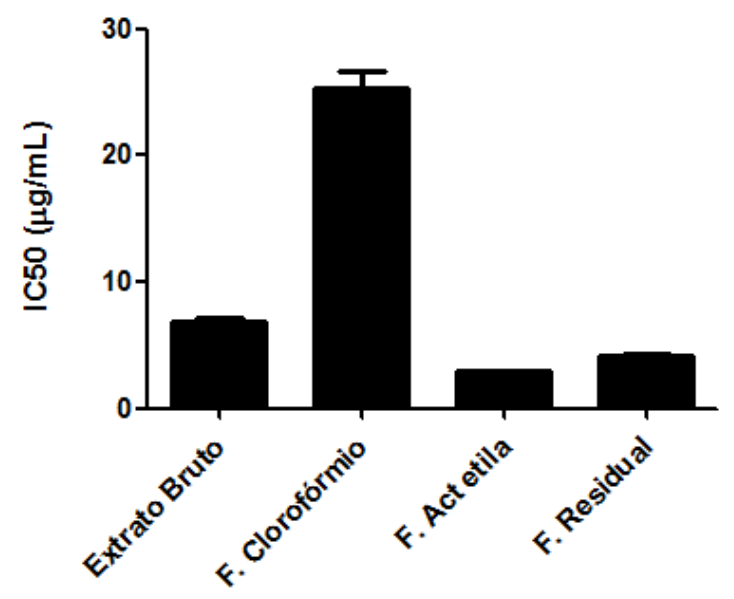

Os resultados são expressos como a média \pm SEM (n=3).

É factível afirmar através do gráfico que entre as frações analisadas a fração acetato de etila obteve melhor resultado, apresentando sequestro de radical livre (SRL) igual a 2,93 $\pm 0,08$ $\mu \mathrm{g} / \mathrm{mL}$, seguido da fração residual que apresentou $4,01 \pm 0,20 \mu \mathrm{g} / \mathrm{mL}$ e extrato bruto com $6,91 \pm 0,22 \mu \mathrm{g} / \mathrm{mL}$, entretanto a fração clorofórmio obteve resultado insatisfatório comparado aos demais, com seu SRL respectivamente igual a $26 \pm 1,39 \mu \mathrm{g} / \mathrm{mL}$.

Pertencente a classe de metabólitos secundários e com uma distribuição extensiva no reino vegetal, Coutinho et al. (2009) afirma que os flavonoides constituem um dos grupos fenólicos mais significativos e diversificados dentre os produtos de origem natural. Segundo Araújo et al. (2015) em sua quantificação e identificação destes compostos em extratos de jacareúba, pôde-se observar a composição em $8.07 \pm 0.15 \mathrm{mg} / \mathrm{g}$ teor de flavonóides totais na espécie. Estes flavonóides podem ser responsáveis pela atividade antioxidante e tendem a ser extraídos com mais frequência por meio da fração acetato de etila.

\section{CONCLUSÃO}

Após a análise dos resultados, expressos em $\mathrm{IC}_{50}$, pôde-se concluir que os extratos obtidos a partir das cascas da espécie Calophyllum brasiliense tiveram bons resultados, entretanto a fração acetato de etila apresentou melhor sequestro de radical livre em relação às demais, tal explicação possivelmente pode estar relacionada ao alto teor de polifenóis.

\section{AGRADECIMENTO}

Os autores agradecem ao Conselho Nacional de Pesquisa (CNPQ) pelo apoio fornecido ao trabalho e ao Instituto de Pesquisas Cientificas e Tecnológicas do Estado do Amapá pelo fornecimento das amostras a este projeto vinculadas.

\section{REFERÊNCIAS BIBLIOGRÁFICAS}


ALVES, Q. C.; DAVID, J. M.; DAVID, J. P.; BAHIA. B. M. V; AGUIAR. R. M. Métodos para determinação de atividade antioxidante in vitro em substratos orgânicos. Química Nova. v. 33, n. 10, p. 2202-2210, 2010.

ARAÚJO, V. A. P de.; NUNES, A. R.; LUCAS, R.; SILVA, G. A da. Total flavonoid content for standardization of amazonian commercial plant extracts. In: international conference of chemical and biochemical engineering, 2015, Paris. Anais ... Paris, 2015.

BRAND-WILLIAMS, W.; CUVELIER, M.E.; BERSET, C. Use of a free radical method to evaluate antioxidant activity. LWT - Food Science and Technology. v. 28, n. 1, p. 25-30, 1995.

BIANCHI, M.L.P.; ANTUNES, L.M.G.. Free radicals and the main dietary antioxidants. Revista de Nutrição., v. 12, n. 2, p. 123-130, 1999.

BOTREL, M. C. G.; de SOUZA, A. M.; de CARVALHO, D.; PINTO, S. I. do C.; MOURA, M. C. de Oliveira.; ESTOPA, R. A. Caracterização genética de Calophyllum Brasiliense Camb. em duas populações de mata ciliar. Sociedade de Investigações Florestais., v. 30, n. 5, p. 821-827, 2006.

COUTINHO, M.A.S.; MUZITANO, M.S.; COSTA, S.S. Flavonoides: potenciais agentes terapêuticos para o processo inflamatório. Revista Virtual de Química, v.1, p. 241-256, 2009.

FANHANI, A. P. G.; FERREIRA, M, P. Agentes antioxidantes: seu papel na nutrição e saúde dos atletas. SaBios- Revista de Saúde e Biol. v. 1, n. 2, p. 33-41, 2006.

HAIDA, K. S.; SILVA, F. J.; COELHO, R. M.; LIMA, D. S. ABRÃO, R. M.; HAIDA, K. Y.. Caracterização físico-química e atividade antioxidante de amoreira-preta (Morus nigra L.). Revista Brasileira de Ciências da Saúde, ano 12, n. 2014.

MILITAL, F. de L.; FURLAN, M. R. Alimento funcional através do uso de ocimum basilicum L. (manjericão) como aromatizante de tempero. Revista Acadêmica Oswaldo Cruz. ISSN 2357-81873. ano 1, n.4, 2014.

NAVARRO, E. C. Viabilidade econômica do Calophyllum brasiliense (Guanandi). Revista científica eletrônica de engenharia florestal. v. 9, n. 9, 2007.

SOUSA, C. M. de M.; SILVA, H. R.; VIEIRA-JR, G. M.; AYRES, M. C. C.; COSTA C. L. S.; ARAÚJO, D. S.; CAVALCANTE, L. C. D.; BARROS, E. D. S.; ARAÚJO, P. B. de M.; BRANDÃO, M. S.; CHAVES, M. H. Fenóis totais e atividade antioxidante de cinco plantas medicinais. Quimíca Nova. v. 30, n. 2, p. 351-355, 2007. 